\title{
Exploring Buddhism as a 'Tool' to Support Well-Being: An Interpretative Phenomenological Analysis of Western Adopters' Experiences
}

\author{
Li Laurent $^{1} \cdot$ David Sheffield $^{2} \cdot$ Fiona Holland $^{2}$ (D)
}

Accepted: 25 May 2021 / Published online: 14 July 2021

(c) The Author(s) 2021

\begin{abstract}
Buddhism is an ancient religion and philosophy of living that is practised worldwide. More recent interest in mindfulness as a practice and intervention in the West has highlighted Buddhist-derived concepts as useful in supporting health and well-being. As a result, the desire to understand Buddhism in its more complete form has strengthened. Although research into mindfulness and compassion is growing, there is a new interest in secondgeneration mindfulness, i.e. interventions that draw upon a more holistic use of Buddhist practices. To date, little research has explored this in Western contexts. For the current study, Nichiren Buddhists from the United Kingdom who had been practising for at least three years were recruited. Semi-structured interviews were conducted to explore their experience of this practice and how it informed their approach to daily life and, in particular, their health and well-being. Interpretive phenomenological analysis was employed as a method to understand the participants' experiences. Three themes were generated using an inductive approach: (1) finding meaning- "All experiences have got so much value now" - which reflected the participants' determination to seek purpose and value in all aspects of their life; (2) Buddhism as a needed 'tool'- "I use it all the time" — which revealed their practice as an important method to help them manage their lives; and (3) agency_-'I'm in control of my destiny"-which highlighted the participants' engagement (supported by their Buddhist practice) in taking responsibility for their actions and responses. Findings indicate the need for future studies to further explore Buddhism as a mechanism for enhancing and sustaining well-being.
\end{abstract}

Keywords Interpretative phenomenological analysis $\cdot$ Buddhism $\cdot$ Well-being $\cdot$ Secondgeneration mindfulness-based interventions $\cdot$ Buddhist practice

Li Laurent

lilaurent@outlook.com

Fiona Holland

f.g.holland@derby.ac.uk

1 Mental Health Social Worker, University of Derby, School of Psychology, Kedleston Road, Derby DE22 1GB, UK

2 School of Psychology, University of Derby, Kedleston Road, Derby DE22 1GB, UK 
Psychologists first attempted to understand Buddhism half a century ago, exploring its traditions and values and introducing its concepts into Western conversation (Segall, 2012). It has been described variously as a "religion of no-religion" (Watts, 1996, p. 1), as a lifestyle choice, and as a cultural institution (Safran, 2003). Whilst it is now most widely identified and accepted as a philosophy, with no deity and only concepts by which to live (Soka Gakkai International (SGI)-UK, 2016), its classification and meaning remain largely ambiguous (Keown, 2013). Although conceptually elusive, Buddhism is firmly established within the Western world (Wuthnow \& Cadge, 2004). with $0.4 \%$ of the population of England and Wales reporting as Buddhist (Office for National Statistics, 2011).

Buddhism has been recognised for its emphasis on the individual, self-awareness, and personal development (Stein, 2017). For emotionally complex human beings in a continuously developing and advancing world (Berk, 2007), maintaining well-being has become an increasingly difficult task (Reinecke \& Oliver, 2016), and the need for effective approaches and interventions is apparent. As such, Buddhist concepts and practices are of interest as their use may provide a compassionate and direct response to human dilemmas that challenge or undermine well-being (Segall, 2012). Specifically, research has identified that utilising Buddhist practices can lead to benefits, including increased feelings of contentment, resilience, and focus (Fraser, 2013) and a positive sense of well-being (Wiseman \& Brasher, 2008).

The first generation of mindfulness-based interventions (MBIs) were secularized and distanced from the spiritual and active aspects of Buddhist meditative practices. MBI is a simplified and Westernised version of its parent Buddhist practice (Samuel, 2015) that "focuses attention in a particular way: on purpose, in the present moment, and non-judgmentally" (Kabat-Zinn \& Zinn, 2013, p. 4). Recent research has highlighted the value of mindfulness practice, and practitioners have been keen to employ it as a clinical intervention (Keng et al., 2011). Mindfulness techniques have been shown to foster the improvement and maintenance of positive well-being (Prazak et al., 2012; Samuel, 2015; Van Gordon et al., 2016). Additionally, mindfulness practice has been found beneficial in terms of attention regulation, emotional regulation, and self-awareness (Hölzel et al., 2011). Mindfulness has been considered highly accessible for people of varying cultural and social backgrounds (Baer, 2011), and there have been calls for it to be made more readily available within some healthcare systems (National Health Service, 2017; Mental Health Foundation, 2010).

However, mindfulness is not without its critics. Recent research has shown that mindfulness in isolation from Buddhist practice can lead to adverse negative effects such as somatic, psychological, and neurological problems (Farias \& Wikholm, 2016). For example, Lomas et al. (2015) reported that a proportion of male mindfulness meditation practitioners, including some who had become disillusioned with the practice, reported exacerbations of mental health issues such as anxiety and depression. In addition, there are concerns about the ethics of nonjudgemental awareness as it may encourage passivity (Van Gordon et al., 2015) and so may place the practitioner's or another individual's well-being at risk. Removing mindfulness meditation from the social context in which it originated may change the nature and effects of the practice (Kirmayer, 2015). Accordingly, practitioners have developed a second generation of mindfulness interventions that acknowledge their Buddhist foundations (Van Gordon et al., 2015).

Research has previously shown that using Buddhist practices can have both positive psychological and physical health effects. In a review of 43 empirical studies published between 1980 and 2003, Weaver et al. (2008) found an increase in the number of articles reporting health benefits of Buddhism. More recently, it has been found that adopting beliefs of Buddhism such as self-regulation, compassion, and kindness may result in 
effective treatments for a wide range of psychopathologies, including mood disorders, substance-use disorders, and mental illness (Shonin et al., 2014). In one study, Zen trainees in Japanese monasteries who practised regular rigorous meditation demonstrated high quality-of-life scores and high levels of general mental health (Shaku et al., 2014). Additionally, Buddhist concepts have been successfully incorporated into mind-body interventions, and studies have shown significant reductions in depressive symptoms (Chan et al., 2011; Manicavasgar et al., 2011; Marchand, 2012; Piet et al., 2012), enhanced loving-kindness (Fredrickson et al., 2008), increased compassion (Allen \& Knight, 2005), and improved feelings of equanimity (Bitner et al., 2003) in participants.

In comparison to mindfulness and more isolated Buddhist concepts (e.g., compassionbased interventions), Buddhism in its more holistic form has been relatively neglected (Desbordes, 2016). Whilst Buddhist philosophy has garnered some interest in both science and medicine (Britton et al., 2014), much of the research regarding Buddhism has concerned its individual concepts rather than its holistic or complete form (Shonin et al., 2014). Limited studies have attended to this. Lindahl, Fisher, Cooper, Rosen, and Britton (2017) completed an extensive mixed-methods investigation into outcomes of practice in Western Buddhist practitioners and identified a range of experiences, both positive and negative. In another phenomenological study, meditation-induced light experiences were explored among American adopters of Buddhism (Lindahl et al., 2014). However, similarly detailed accounts pertaining to well-being are scarce. Lomas et al. (2012) interviews with male British meditators revealed that Buddhism offered an attractive 'package' in terms of supporting a multidimensional model of well-being that encompassed biological, psychological, and social terms, and Van Gordon et al.'s (2016) study with British adults who had fibromyalgia syndrome suggested that meditation awareness training was perceived to enhance psychosomatic well-being, spiritual growth, and sense of citizenship. It is apparent that research into more complete Buddhist practices as used by Westerners is still limited and that relatively little is known about the lived experience of Western adopters of Buddhism. There is a need for a better understanding of what Buddhism means to individuals and how they apply their practice in everyday life in the West.

This study aims to consider the experience of well-being and Buddhism via a phenomenological approach that embraces the complexity of human psychology itself (Smith et al., 2009). Previous researchers exploring Buddhism have predominantly taken a positivist approach (Knight, 2004), which enables the identification of relationships (e.g., between employing Buddhist practices and improved mental health), but interpretation of such relationships is unexplored. Few phenomenological qualitative studies that explore Western adopters' experiences of Buddhist practices using a phenomenological approach have been conducted to date (Lindahl et al., 2014, 2017; Van Gordon et al., 2016). This study uses interpretive phenomenological analysis (IPA; Smith, 1996) to explore how Westerners who practice Buddhism make sense of their experience. IPA has been used in studying meditation awareness training (Shonin \& Gordon, 2015; Van Gordon et al., 2016) and mindfulness-based cognitive therapy (Williams et al., 2011; Zoysa et al., 2014). Because Buddhism has been defined as a subjective individual experience (Bojanowska \& Zalewska, 2016) and is a practice concerned with the human experience (Wallace, 2003), IPA is an appropriate methodology as it employs an idiographic approach that focuses on lived experience (Smith et al., 2009). To maintain a more homogeneous sample per IPA guidelines (Smith, 1996; Smith \& Osborn, 2008), one style of Buddhism was selected, Nichiren Buddhism. The study aimed to understand how Buddhism practice was experienced and used in people's daily lives. It was hoped that any applications for well-being that were revealed might offer insight into potential transferability across a wider context. 


\section{Method}

\section{Participants}

The researchers recruited United Kingdom-based Nichiren Buddhists who had received their gohonzon, a calligraphic scroll that depicts this Buddhist faction's values and beliefs and is utilised in daily practice for directed chanting (Soka Gakkai International (SGI)UK, 2016). The attainment of the gohonzon reflects the commitment and understanding of the Nichiren practitioner and is typically achieved after a period of dedicated, long-term practice. The researchers therefore believed that such individuals would be able to provide a detailed and insightful interview regarding their experience. As effective practice is predicated on consistency and commitment (Soka Gakkai, 2021), their experience, as opposed to that of more novice practitioners, would allow greater access to their understandings of the potential utility of the practice across time and in a variety of situations they had encountered.

Four participants were recruited via networks known to the first researcher; three were female and one was male. The details of the participants are listed below (see Table 1), with pseudonyms used to protect their anonymity.

The sample size was in line with recommendations for IPA (Smith \& Osborn, 2008) as an idiographic approach that investigates individual cases is preferable in order to allow for a more intense scale of enquiry and analysis (Smith et al., 1999). As this study is the first to take a phenomenological approach to explore Western adopters of Buddhism, a small, purposive sample (Smith et al., 2009) within one style of Buddhism was appropriate.

\section{Procedure}

The current research employed a qualitative, phenomenological approach that sought to understand the complexities of the human experience (Lehnert et al., 2016). This philosophical approach of IPA focuses on human experience (Smith et al., 2009) and how the individual makes sense of it (Smith, 2004). It is idiographic (Smith, 1995) in that it allows the researcher to concentrate on individuals' unique experiences, seeking to determine meaning from subjective phenomena. It is inductive as the researcher interprets the dataset without a priori themes and with awareness of the iterative hermeneutic processes involved (see Smith, 2007), and it is interrogative in that the researcher evaluates how the findings fit with extant theory and knowledge (Hamill et al., 2010).

Ethical approval was granted by the university where the research was based. All participants provided informed consent and understood their purpose within the research, including their right to withdraw at any time during and up to 2 weeks following their interview.

Table 1 Participant Information

\begin{tabular}{lll}
\hline Pseudonym & Age & $\begin{array}{l}\text { Years } \\
\text { Practising } \\
\text { Buddhism }\end{array}$ \\
\hline Penny & 25 & 6 \\
Daniel & 58 & 30 \\
Jennifer & 62 & 16 \\
Natasha & 54 & 3 \\
\hline
\end{tabular}


The first author recruited the participants from a known community of Buddhism practitioners in the United Kingdom. She had experience practising Nichiren Buddhism for over two years. It was an asset to have an insider's view (Smith et al., 2009) as familiarity with the Buddhist terminology supported the analytical process and prevented misinterpretation of concepts that were central to the practice. However, to ensure the validity of the analysis, the first author maintained a reflexive journal and underwent regular supervision with the second and third authors during the analysis process.

A semi-structured interview approach was utilised in order to guide the interviews whilst allowing each participant to freely elaborate on his or her experience and a narrative to naturally develop (Galletta \& Cross, 2013). The interview questions were designed based on the IPA guidelines (Smith et al., 2009) and allowed the individual to explore what Buddhism meant to them, how it informed their life, and how this was experienced in relation to well-being. Upon completion of the interview, all individuals were thanked for their participation, and a written debrief form was issued. Participants also had the opportunity to ask questions. Interviews were audio-recorded and transcribed verbatim by the first author.

\section{Data analysis}

An inductive phenomenological approach was taken; i.e. individual and then cross-case themes were developed from the raw data with the focus on interpreting the impact of Buddhist practice as it is subjectively experienced. The transcripts were analysed in accordance with Smith et al.'s (2009) recommendations. Each individual transcript was read thoroughly multiple times in order to gain a rich and detailed understanding of the participant's experience. Once familiar with each transcript, exploratory and interrogative comments were recorded in addition to interpretations of underlying meaning from the narrative. Particular attention was given to linguistic elements such as pronoun use and metaphors (Shinebourne \& Smith, 2010). Conceptual-level themes were developed for each participant, and reflexive notes were made throughout. As the analysis progressed, the idiographic themes were clustered for each participant, and, finally, key cross-case conceptual themes were generated. The initial themes were developed by the first author. Via supervision, codevelopment and discussion, final themes were agreed on. The validity of this study was assessed in accordance with Yardley's (2000) criteria.

\section{Findings}

During the analytic process, three main themes were developed: (1) finding meaning: "All experiences have got so much value now"; (2) Buddhism as a daily 'tool': "I use it all the time"; and (3) agency: "I'm in control of my destiny". These collectively give insight into the meaning-making of the participants and the role Buddhist practice plays in their everyday lives.

\section{Theme 1: Finding meaning: "All experiences have got so much value now"}

All participants directly or indirectly discussed value, meaning, and purpose throughout their interviews. Through the lens of Buddhism, they saw life as a sequence of opportunities rather than a definitively positive or negative experience. This supported an enhanced 
sense of well-being. Penny described her life before and after practising Buddhism and recalled how, prior to adopting Buddhist practice, her life had had little meaning:

It was bland, it was a bland life. I just got on with everyday life like it was what I had to do. Had to go to work, had to do this, now I find purpose, I, I want to get up, I want to go to work, I want to push myself and challenge myself whereas before I was just living just [a] bit basic life.

Here, Penny's life was sustaining her but it had no flavour. Her day-to-day activities were necessary but dull and repetitive, and her language reflects this lack of energy, agency, and enthusiasm. She described life as a chore-"I had to," "I just got on with it"-an obligation rather than a choice or desire. She attributed Buddhism to helping her to cultivate a change of perspective as, although her daily activities reportedly had not changed, her perception of them had. She searched for value through her Buddhist practise to make "the most" of her experiences.

Daniel similarly discussed how Buddhism allowed him to reinterpret his everyday experiences. In contrast to Penny, he did not reinterpret the potential in his day but rather accepted his negative experiences and found benefit within them:

If I feel low today, I feel low today. You know, I almost, I almost feel joy that I'm allowed, that I can feel that there's a feeling. I'm alive, I can feel depressed, I can feel, I can feel anxious, I can feel-I can suffer. But there's, behind it all there's a joy because if I wasn't alive I couldn't experience these-it's like I crave, I crave experience, I crave, you know, it's all experience, all experiences have got so much value now. It's very difficult, it's, it's a bit like curry or salt and pepper or, you know, it's . . . you can't know happiness without suffering, you can't, you know.

Daniel's acceptance and gratitude for his "low" moods is clear. His repetitive use of "I can" highlights his agency and his appreciation of the ability to "feel" and experience all emotions and sensations, even the ability to "suffer". He sees every aspect of life as valuable because "it's all experience". This perspective shift encourages his cultivation of a sense of the worth of each experience. Daniel "craves" experience, highlighting his hunger and desire for life and meaning. Similar to Penny's experience of overcoming blandness, Daniel interprets Buddhism as a spice which enhances and gives flavour to his life experiences. Practising Buddhism has helped both Penny and Daniel reappraise their perspectives towards their daily activities and gain greater meaning from life.

Jennifer also accepted that there are inevitable negative aspects in life and, similarly, her attitude was to embrace each experience:

It's just an exciting journey, it really is and you know, we will become ill, we will die, you know, there will be divorces, there will be all those things. But it's, it's how it's changed my attitude towards everything that's made a vast difference, instead of being a victim to it, you know, right, where can I win with this?

Like Daniel, Jennifer accepts and embraces challenges in a pragmatic and positive way. In her shift from "victim" to winner through her Buddhist interpretation, we see her feelings of self-esteem and self-efficacy; she now sees herself as capable of improving her life regardless of the inevitable struggles.

In this theme, the participants' broader perspectives on making meaning out of life experiences were clearly influenced by their practice. In the following theme, they identify individual components of their practice that they harness to support their well-being. 


\section{Theme 2: Buddhism as a daily "tool" — "I use it all the time"}

The participants reported utilising Buddhism in varying ways throughout their daily life as a way of enhancing individual experiences. Jennifer used a metaphor to describe how practising had enabled her to address the issues she faced and had experienced previously:

Practice is a bit like having a glass filled with lovely clear water, and chanting is like a silver spoon that we stir at the bottom of the glass and all this sediment comes up, and that's what we need to do really to change this deep-rooted, very often disrespect for our own lives and for life itself really, so I needed a tool to be able to do that, and it's just that it works for me.

Jennifer uses Buddhist chanting as a way of access darker and more challenging thoughts and emotions; her practice acts as a valuable catalyst for change, a 'silver spoon' that allows these to be brought to her attention. She considers her life and her practice as interchangeable, fluid, and naturally part of her. Her practice fluctuates between functioning as a necessary 'tool' that she uses-the spoon-and an inherent resource-the waterfilled glass. Jennifer's use of the Buddhist practice of chanting reportedly helped her move from a sense of being frozen by fear to being able to have agency and make changes. She describes this shift: "Sometimes I'll be pole-axed into fear. I'm not anymore. I'll still feel frightened, but I know when I chant, I can start to feel better again".

Jennifer's use of "pole-axed" suggests a forced, powerless state of fearfulness that inherently limited her. This extract reveals a number of tense changes as she shifts from using "I'll be pole-axed" and "I'll still feel frightened" in the present tense to saying "I'm not anymore" about her past emotional states. We interpret this reinterpretation of her emotional state as indicating that this continues to be an ongoing process. We interpret her current self as being more proactive and agentic as she uses tools within her practice to "feel better" and feel more in control.

Penny used chanting as a method to process and manage emotional aspects of her life: I need to chant every day, twice a day, so I can get the fullness of my everyday life. If I don't chant in the morning, I'm not, I'm not getting up, I'm not doing my routine, I'm not getting my boy to school, but when I do chant, I've got all the energy in the world to go and do what I need to do, and my Buddhism, it helps me in relationships, it helps me at work, it helps me focus on my day, everyday life. It helps me get through challenges at work, erm, especially with people that I conflict with.

Her practice is clearly an essential requirement to gain the "fullness" of meaning in her life. The repeated use of "I'm not" demonstrates her definitive view on the limitations she has if she does not chant. Her practice is interpreted as an essential and enhancing resource. In an earlier part of the interview, Penny referred to feeling like "the whole world" was against her when she did not practice; this contrasts with her experience of "I've got all the energy in the world" when she did. Her chanting enables her to dramatically change her perspective, and in this way it functions as a transformative device.

Natasha, like Penny, spoke of how she used Buddhism within her relationships and daily life as something to grasp when she felt in need of support. By using it as a source of strength, she was able to change how she engaged with the people around her. She stated:

That's where I pull it and that's where I use it all the time. That's where I use it all the time. I think before I make phone calls, I think before I text. I think and I think about the other person as much as I think about myself, and, it, it was, before, it was like 
it was all about the other person's need or all about my need - there was no middle, no win-win. I'd got to win or they'd got to win because I was in this constant state of fight or flight, yeah, so I was either giving everything or trying to keep everything, so it's changed that.

Natasha actively draws upon her practice as if it were something attainable that she could physically grasp or "pull" on for support and stability. Buddhism, for her, involves her action, input, and effort. She repeats "all the time", suggesting the practice is a purposeful, practical, and well-utilised resource-a consistently supportive structure in her life. She frames her previous relationships as competitive, ones in which someone had to "win" or lose. She depicts Buddhism as a tool that has enabled her to regulate her stress response ("fight or flight") and find greater balance. Natasha repeats the phrase "I think"; this suggests that Buddhism has enhanced her ability to be contemplative and mindful within her interactions with others, lifting her from "need", giving her space, time, and distance to manage the more impulsive, push me-pull you situations.

Participants used the tools from their Buddhist practice in ways that supported the pragmatics of their daily life and also helped them navigate emotional situations. The regular use of these ways of thinking or modes of practising enhanced their sense of active engagement with the world. The following theme highlights the pros and cons of this agency.

\section{Theme 3: Agency: "I'm in control of my destiny"}

Participants identified several ways in which they took ownership of the problems they faced in life, and they attributed this change to their adopted Buddhist practices. They saw themselves as being agents of their lives and in doing so gained a sense of control. Daniel reflected on how studying Buddhism had enabled him to abandon coping mechanisms he had once used. As a result, he was able to engage with his life with greater agency, although he recognised this was not always an easy path:

We leave behind all our comfort blankets and safety nets, and when it actually gives you the power to actually write your own script and really decide how you wish to live your life then it's, it's an incredible responsibility to take on, you know, because you've got no one to blame and it's, to me it's, it's, it's very much like Pandora's box. There's been many times I've wished that I didn't know what I know. There's many times when I wished I'd never started practising and I could just, it's a bit like The Matrix where you take a pill and you go back into a state of ignorance, you reconnect back into the matrix.

We interpret Daniel's "comfort blankets and safety nets" as referring to protective psychological mechanisms that kept him feeling safe, buffering him from the responsibilities that come with conscious awareness. In letting go of them, he recognised that he was removing restrictions on his life that had protected and insulated but also limited him. Buddhism helped him to gain agency; this contrasts with his previous view of seeing himself as a more passive victim, similar to Jennifer. His ability to take ownership of his life and its direction was overwhelming, "like Pandora's box". His previous lack of awareness of his capabilities or his sense of identity contrasts with his newfound ability to "write your own script"; he has a greater sense of self, steps into his responsibilities, and engages more fully with his life. The reference to the film The Matrix alludes to the pros and cons of his astute self-awareness and consciousness. In some ways, this burdens him, as Buddhism makes him solely accountable for his life. At times, the overwhelming nature of his awareness is 
cast in sharp contrast to the security blanket of ignorance, which appeals to him in times of discomfort.

Across the data set, participants did not report that their Buddhist practice always helped their life feel easier as they had added a level of work to their daily life. In the following extract, Natasha discussed how she was taking responsibility for difficulties in her life and how her perspective had changed towards approaching them:

I still have my moments. I managed to create my own little hell over Christmas [laughs], you know, everybody's got their inner child, haven't they? It's, you know, but, yeah, I do feel totally different. I'm in control of my destiny, not the other way round, and that was the thing that I couldn't, because of my history and my childhood, I'd always felt like the world played by a set of rules that I didn't understand, that I didn't get.

Natasha recognises in this extract that she is responsible and accountable for situations today-she created her "own little hell". This contrasts with her earlier reported experiences of feeling like others controlled her, as though she were part of a game, disempowered yet having to obey arbitrary rules. Her current sense of agency to control her destiny suggests that she is in control of her life, even in the challenging times. With Buddhism as a tool, she has liberated herself from the perspective of the external world as controlling her.

Jennifer also identified that her struggles were directly linked to her own actions. She discusses her previous marriage and reflects back on her life in a practical manner:

It's a bit like standing on this table and trying to pick it up at the same time. There's no chance of doing it, but I never realised it, so the frustration grew and grew and we [she and her ex-husband] became more and more hermit-like together and as I say very fearful, and so I just thought that was my lot, I wouldn't be able to do anything about it, and I just felt that we did ourselves an absolute disservice really and that we could have had a great life together if I'd have been stronger, if I'd have had something in my life that empowered me, so my fight was always against him, I didn't realise it was against, you know, deep down it's me, and this practice showed me that.

The use of the metaphor of 'standing on this table' illustrates the immovable force of her own lack of inner awareness. She now attributes her greater insight to her Buddhist practice. She suggests that Buddhism has allowed her to reflect objectively upon her behaviour with self-acceptance and clarity. She posits that practising Buddhism has enabled her to remove the emotional subjectivity that clouded her self-awareness during this time in her life and has helped her to move away from the fear and frustration she previously experienced. This frustration and "fight" appeared to be embedded within her previous lack of agency. Her previous view of her life was passive, limited, and fatalistic: "that was my lot". In contrast, she suggests that Buddhism has "empowered" her and enabled her to gain an enhanced sense of resilience. She can see, upon reflecting back, that this insight could have enabled her to be more capable of changing the outcome of even the most significantly upsetting part of her life. We hear her regret and her sense of wistfulness about this and her clarity that her practice has supported her ability to be in healthier future relationships.

In summary, our analysis presents Nichiren Buddhism as a practical and emotional tool for maintenance of and contribution to individual well-being. All three themes show how the practice contributed to the participants' welfare and supported them in being more proactive in their lives and better able to cope with difficult emotional and physical experiences. 


\section{Discussion}

The present study used IPA to explore the experience of Nichiren Buddhism in interviewees' daily lives. Three predominant themes were generated, and, collectively, these enhance our understanding of how United Kingdom-born Buddhists use the practice to support their well-being. Whilst each individual's experience of the practice was unique, the themes demonstrate common factors across all four interviews.

The analysis presented reveals the utility of Nichiren Buddhism as it was used proactively and flexibly by all participants in their daily lives. Their experiences suggest that the practice was beneficial to them as they navigated challenges, and it provided a strategy for managing both positive and negative experiences in a healthy and proactive manner. This is a benefit that Lomas et al. (2015) suggested may not be achieved using mindfulness alone; they posited that whilst mindfulness heightens consciousness and engagement with the world, it does not provide psychological mechanisms to manage the issues that inevitably arise from such self-awareness. The current analysis supports Lomas et al.'s argument as across all accounts in the current study, the participants' Nichiren Buddhism practice reportedly helped them develop self-awareness and informed their feelings of self-efficacy, self-esteem, and self-acceptance. Such feelings are not only integral to well-being (Vos et al., 2015) but are also likely to make heightened self-awareness a more manageable and enjoyable experience. For example, Daniel acknowledged that his life was "an incredible responsibility", yet he felt empowered by this realisation rather than incapable of managing his life. It could therefore be argued that extracting individual concepts such as mindfulness may be removing core components of Buddhist tradition that are cultivating exceptional states of well-being (Wallace $\&$ Shapiro, 2006) and that the holistic practice of Nichiren Buddhism equips individuals to manage difficult emotions more successfully. This may explain why adverse effects of using mindfulness in isolation have been identified (Dobkin et al., 2012; Farias \& Wikholm, 2016; Lomas et al., 2015).

The first theme revealed that participants positioned the practice as something that maximised their perception of life. Their accounts revealed a determination to find meaning in all aspects of life, including negative events, which suggests that Nichiren Buddhism is a practice of seeking value and creating positivity. This adds to the research and supports that a more holistic approach to practice can, like mindfulness practice alone, be beneficial in terms of attention regulation, emotional regulation, and self-awareness (Hölzel et al., 2011). Our analysis supported the notion of Nichiren Buddhism as a practice that promoted a sense of acceptance and optimism when participants faced stressors or challenges such as depression, death, and conflict. These findings support previous research that suggests Buddhism and its holistic concepts are able to inform coping methods (Mok \& Tam, 2001) and also offers further insight into how individuals are able to find value in negative events, which makes coping with such difficulties more manageable.

Participants also discussed making the most of obligatory and everyday tasks such as household chores or work, with such tasks being seen as valuable opportunities for personal understanding and development rather than mundane, routine jobs. This reflects the findings of Marques's (2012) study of Buddhism in the workplace in which individuals saw each working day as an opportunity rather than an obligation, enhancing their sense of meaning and value within their actions and roles. Marques (2012) argued that the concepts of Buddhism were utilised successfully, although participants in his study were unaware of their Buddhist origin. The current study, however, demonstrates that when an individual 
understands the practice and its derivation and purposefully adopts this, it can also successfully enhance their lived experience. This suggests that, for some Westerners, a more explicit understanding of the entirety of the practice of Buddhism may not be a barrier (as proposed by Marques, 2012) and that second-generation mindfulness-based interventions are worthy of further practical application (see Shonin et al., 2014; Shonin \& Van Gordon 2015; Van Gordon et al., 2016).

The second theme, Buddhism as a "daily tool", highlighted that participants saw their experience of Buddhism as something practical, beneficial, and useful in everyday life. Each participant reported that they employed the practice not only to determine value within their life but also when combatting stressors and conflicts and facing more significant, emotionally demanding events. It can therefore be concluded that the practice is flexible in its utility, meeting specific needs and supporting some participants in moving towards a more proactive engagement with their lives. Nichiren Buddhism can be interpreted as a tool for positive change, albeit what is changed is subjectively determined. The second theme demonstrates that the practice is not utilised as a faith but rather as an aid to existing values and beliefs. As concerns exist regarding how Buddhist philosophy conflicts with religion (Hagen, 2005), the participants' understanding of their practice helps to elucidate its classification as a nonreligious practice. Participants saw themselves as being wholly responsible for the direction of their lives, with no concept of a deity or authority to which they ascribed. Buddhism was presented as a way of thinking and not as a religion. This has implications for the practice's potential acceptability across wider groups within second-generation meditation-based interventions (see Shonin \& Van Gordon, 2015). The analysis supports previous work which has suggested that participants who employ Buddhist practices gain spiritual growth and a more positive life perspective and that their practice buffers them against feelings of loneliness, lack of purpose, and negative affect (Shonin \& Van Gordon, 2015; Shonin et al., 2014).

The third theme highlights the individuals' ability to take responsibility for their actions and their ability to control and determine their day. The participants understood Nichiren Buddhism to be a way of being in the world that demanded accountability (e.g. Daniel abandoned his "safety nets"). All participants revealed the development or strengthening of an internal locus of control (Rotter, 1966) and self-efficacy (Bandura, 1982), e.g. "it actually gives you the power" (Daniel), removing previous limitations they had perceived. This suggests that by adopting Nichiren Buddhism they gained tools to enhance their ability to successfully direct their lives. We therefore suggest that the adoption of this Buddhist practice can foster transformational experiences. Taking ownership is an important part of well-being and mental health, aiding recovery from mental and physical illness (National Health Service, 2017). The analysis suggests that for these participants Buddhist practice was a useful way to reinforce positive psychological thought processes and might, if future studies find similar outcomes, be utilised as a mechanism for the maintenance of well-being.

The analysis offers insight into the role of Buddhist practice in fostering and maintaining well-being in a small sample of participants. It highlights that their experience of practising Buddhism contributed to their positive perspective, enhanced their self-esteem, and increased their sense of engagement with the world around them-key factors in the continuance of positive mental well-being (National Health Service, 2017). In contrast to Shaku et al.'s (2014) study of Zen trainee monks, who practised rigorously and reported improved mental health and sense of well-being, this study shows that Western adopters of Nichiren Buddhism gained benefits without supervised practice or an affiliation with 
a monastery. This highlights that Buddhist practice can be easily incorporated into typical daily life in the West (in this case, the United Kingdom). It also suggests its utility as a mechanism for the maintenance of well-being. IPA researchers do not seek to generalise their findings from in-depth ideographically sensitive explorations (Smith, 1996; Smith et al., 2009). However, the transferability (Yardley, 2000) of the findings is worthy of consideration, and future studies are recommended to further explore this. The idiographic nature of this approach offers rich insight into the lived experience of participants and contributes to the literature in the arena of second-generation approaches to understanding the potential impact of Buddhist practices in the West. The transferability of this phenomenological study supports the consideration of second-generation Buddhist practices being introduced into the wider population as a self-help strategy in day-to-day life as well as their being offered in a range of formal settings where emotional regulation, psychological coping, and resilience-building are of particular importance (e.g. schools, prisons, rehabilitation centres, hospitals, and care centres).

\section{Limitations and recommendations}

A limitation of this study lies in the nature of IPA itself as different researchers are likely to provide different interpretations of interviews (Smith et al., 2009) because they are influenced by their own life experience or fore-structures. The credibility of the study is maintained by ensuring the voices of the participants are represented throughout (Yardley, 2000). Participants within this study had practised Nichiren Buddhism for varying lengths of time ranging from 3 to 30 years. The congruence of experiences and themes across all interviews suggest that length of engagement in the practice does not determine its utility, benefits, or effects on well-being. However, further research could explore the length of experience as a particular focus. Focusing on more novice practitioners might be particularly useful to explore the utility of Nichiren Buddhism as a mechanism for the fostering and maintenance of well-being in the shorter term. This would help to strengthen the argument for its use in the improvement of well-being and mental health as suggested by previous research (see Shonin et al., 2014).

We acknowledge that findings may vary depending on the Buddhist denomination that is explored as well as the length and experience of practice. As little is understood of the Buddhist philosophy (Shonin et al., 2014), future research could explore different styles of Buddhist practice to gain a greater understanding of how the experience might vary. The current study is the first to take an idiographic approach to understanding the lived experience of Western adopters of Nichiren Buddhist practice. This detailed interpretative analysis revealed similarities in how practitioners of different ages, genders, and experience levels used Buddhism in everyday life in the United Kingdom. Given that an estimated $40 \%$ of Buddhists in the United Kingdom are converts to Buddhism who have adopted its philosophy and practice (Bluck, 2006), further detailed investigation of the experiences across a range of practitioners is warranted.

In summary, this analysis showed that Nichiren Buddhism practice can be used to cultivate positive psychological thought processes and that it was used by United Kingdom practitioners as a mechanism for maintaining well-being. Further studies regarding the use of Nichiren Buddhism or other strands of Buddhist practice are recommended to establish it as a potentially more beneficial practice than the use of mindfulness alone. Moreover, direct comparisons of first- vs. second-generation MBI would aid 
in understanding of the differential benefits and similarities of the two interventions (Shonin et al., 2013).

Authors Contribution All authors contributed to the study conception and design. Material preparation, data collection and analysis were performed by Natalie Laurent under the supervision of Fiona Holland and David Sheffield. The first draft of the manuscript was written by Natalie Laurent and all authors commented on previous versions of the manuscript. All authors read and approved the final manuscript.

Open Access This article is licensed under a Creative Commons Attribution 4.0 International License, which permits use, sharing, adaptation, distribution and reproduction in any medium or format, as long as you give appropriate credit to the original author(s) and the source, provide a link to the Creative Commons licence, and indicate if changes were made. The images or other third party material in this article are included in the article's Creative Commons licence, unless indicated otherwise in a credit line to the material. If material is not included in the article's Creative Commons licence and your intended use is not permitted by statutory regulation or exceeds the permitted use, you will need to obtain permission directly from the copyright holder. To view a copy of this licence, visit http://creativecommons.org/licenses/by/4.0/.

\section{References}

Allen, N. B., \& Knight, W. E. J. (2005). Mindfulness, compassion for self, and compassion for others: Implications for understanding the psychopathology and treatment of depression. In P. Gilbert (Ed.), Compassion: Conceptualizations, research, and use in psychotherapy (pp. 239-262). Routledge.

Baer, R. A. (2011). Measuring mindfulness. Contemporary Buddhism, 12(1), 241-261.

Bandura, A. (1982). Self-efficacy mechanism in human agency. American Psychologist, 27(2), 122-147.

Berk, L. (2007). Development through the lifespan. Pearson.

Bitner, R., Hillman, L., Victor, B., \& Walsh, R. (2003). Subjective effects of antidepressants: A pilot study of the varieties of antidepressant-induced experiences in meditators. Journal of Nervous and Mental Disease, 191, 660-667.

Bluck, R. (2006). British Buddhism: Teachings, practice \& development. Routledge.

Bojanowska, A., \& Zalewska, A. M. (2016). Lay understanding of happiness and the experience of wellbeing: Are some conceptions of happiness more beneficial than others? Journal of Happiness Studies, 17(2), 793-815.

Britton, W. B., Lindahl, J. R., Rael Cahn, B., Davis, J. H., \& Goldman, R. E. (2014). Awakening is not a metaphor: The effects of Buddhist meditation practices on basic wakefulness. Annuals of New York Academy of Sciences, 1307, 64-81.

Chan, A. S., Cheung, M. C., Tsui, W. J., Sze, S. L., \& Shi, D. (2011). Dejian mind-body intervention on depressive mood of community-dwelling adults: A randomized controlled trial. Evidence Based Complementary Alternative Medicine. https://doi.org/10.1093/ecam/nep043

Desbordes, G. (2016). On the relationship between mindfulness and Buddhism (hint: It's complicated). Psyccritiques, 61(23).

Dobkin, P. L., Irving, A., \& Amar, S. (2012). For whom may participation in a mindfulness-based stress reduction program be contraindicated? Mindfulness, 3, 44-50.

Farias, M., \& Wikholm, C. (2016). Has the science of mindfulness lost its mind? BJPsych Bulletin, 40(6), 329-332. https://doi.org/10.1192/pb.bp.116.053686

Fraser, A. (2013). The healing power of meditation: Leading experts on Buddhism, psychology, and medicine explore the health benefits of contemplative practice. Shambhala.

Fredrickson, B. L., Cohn, M. A., Coffey, K. A., Pek, J., \& Finkel, S. M. (2008). Open hearts build lives: Positive emotions, induced through loving-kindness meditation, build consequential personal resources. Journal of Personality \& Social Psychology, 95(5), 1045-1062.

Galletta, A., \& Cross, W. E. (2013). Mastering the semi-structured interview and beyond: From research design to analysis and publication. NYU Press.

Hagen, S. (2005). Book review: Buddhism is not what you think: Finding freedom beyond beliefs. Nova Religio, 9(2), 137. 
Hamill, R., Carson, S., \& Dorahy, M. (2010). Experiences of psychosocial adjustment within 18 months of amputation: An interpretative phenomenological analysis. Disability and Rehabilitation, 32, 729-740.

Hölzel, B. K., Lazar, S. W., Gard, T., Schuman-Olivier, Z., Vago, D. R., \& Ott, U. (2011). How does mindfulness meditation work? Proposing mechanisms of action from a conceptual and neural perspective. Perspectives on Psychological Science, 6(6), 537-559.

Kabat-Zinn, J., \& Zinn, J. K. (2013). Mindfulness meditation in everyday life. BettterListen! LLC.

Keng, S. -L., Smoski, M. J., \& Robins, C. J. (2011). Effects of mindfulness on psychological health: A review of empirical studies. Clinical Psychology Review, 31(6), 1041-1056.

Keown, D. (2013). Buddhism: A very short introduction (Vol. 3). Oxford University Press.

Kirmayer, L. J. (2015). Mindfulness in cultural context. Transcultural Psychiatry, 52(4).

Knight, J. (2004). Religion and science: Buddhism on the brain. Nature, 432(7018), 670.

Lehnert, K., Craft, J., Singh, N., \& Park, Y. H. (2016). The human experience of ethics: A review of a decade of qualitative ethical decision-making research. Business Ethics: A European Review, 25(4), 498-537.

Lindahl, J. R., Kaplan, C. T., Winget, E.M., \& Britton, W. B. (2014). A phenomenology of meditationinduced light experiences: Traditional Buddhist and neurobiological perspectives. Frontiers in Psychology, 4, 973.

Lindahl, J. R., Fisher, N. E., Cooper, D. J., Rosen, R. K., \& Britton, W. B. (2017). The varieties of contemplative experience: A mixed-methods study of meditation-related challenges in Western Buddhists. PLoS One, 12(5), e0176239.

Lomas, T., Cartwright, T., Edginton, T., \& Ridge, D. (2012). 'I was so done in that I just recognized it very plainly, "You need to do something"': Men's narratives of struggle, distress and turning to meditation. Health, 17(2), 191-208.

Lomas, T., Cartwright, T., Edginton, T., \& Ridge, D. (2015). A qualitative summary of experiential challenges associated with meditation practice. Mindfulness, 6, 848-860.

Manicavasgar, V., Parker, G., \& Perich, T. (2011). Mindfulness-based cognitive therapy vs cognitive behaviour therapy as a treatment for non-melancholic depression. Journal of Affective Disorders, 130(1-2), 138-144.

Marchand, W. R. (2012). Mindfulness-based stress reduction, mindfulness-based cognitive therapy, and Zen meditation for depression, anxiety, pain, and psychological distress. Journal of Psychiatric Practice, $18(4), 233-252$.

Marques, J. (2012). Making Buddhism work @ work: The transformation of a religion into a seasoned ethical system. Journal of Management Development, 31(6), 537-549.

Mental Health Foundation. (2010). Be mindful report. https://www.mentalhealth.org.uk/publications/bemindful-report

Mok, E., \& Tam, B. (2001). Stressors and coping methods among chronic haemodialysis patients in Hong Kong. Journal of Clinical Nursing, 10(4), 503-511.

National Health Service. (2017). Stress, anxiety and depression. http://www.nhs.uk/Conditions/stressanxiety-depression/Pages/improve-mental-wellbeing.aspx

Office for National Statistics. (2011). Key statistics for England and Wales: http://ons.gov.uk

Piet, J., Wurtzen, H., \& Zachariae, R. (2012). The effect of mindfulness-based therapy on symptoms of anxiety and depression in adult cancer patients and survivors: A systematic review and meta-analysis. Journal of Consulting and Clinical Psychology, 80(6), 1007-1020.

Prazak, M., Critelli, J., Martin, L., Miranda, V., Purdum, M., \& Powers, C. (2012). Mindfulness and its role in physical and psychological health. Applied Psychology: Health and Well-Being, 4(1), 91-105.

Reinecke, L., \& Oliver, M. B. (2016). The Routledge handbook of media use and well-being: International perspectives on theory and research on positive media effects. Routledge.

Rotter, J. (1966). Generalized expectancies for internal versus external control of reinforcement. Psychological Monographs, 80(1), 1-28.

Safran, J. D. (2003). Psychoanalysis and Buddhism: An unfolding dialogue. Wisdom Publications.

Samuel, G. (2015). The contemporary mindfulness movement and the question of nonself. Transcultural Psychiatry, 52(4), 485-500.

Segall, S. R. (2012). Encountering Buddhism: Western Psychology and Buddhist teachings. SUNY Press.

Shaku, F., Tsutsumi, M., Goto, H., \& Arnoult, D. S. (2014). Measuring the effects of Zen training on quality of life and mental health among Japanese monk trainees: A cross-sectional study. Journal of Alternative and Complementary Medicine, 20(5), 406-410.

Shinebourne, P., \& Smith, J. A. (2010). The communicative power of metaphors: An analysis and interpretation of metaphors in accounts of the experience of addiction. Psychology and Psychotherapy: Theory, Research and Practice, 83, 59-73. 
Shonin, E., \& Van Gordon, W. (2015). Managers' experiences of meditation awareness training. Mindfulness, 6, 899-909. https://doi.org/10.1007/s12671-014-0334-y

Shonin, E., Van Gordon, W., \& Griffiths, M. D. (2013). Meditation awareness training (MAT) for improved psychological well-being: A qualitative examination of participant experiences. Journal of Religion \& Health, 3(53), 849-863.

Shonin, E., Van Gordon, W., \& Griffiths, M. D. (2014). The emerging role of Buddhism in clinical psychology: Toward effective integration. Psychology of Religion and Spirituality, 6(2), 123-137.

Smith, J. A. (1995). Semi-structured interviewing and qualitative analysis. In J. A. Smith, R. Harre, \& L, Van Langenhove (Eds.), Rethinking Methods in Psychology (pp. 9-26). London: Sage.

Smith, J. A. (1996). Beyond the divide between cognition and discourse: Using interpretative phenomenological analysis in health psychology. Psychology and Health, 11(2), 261-271.

Smith, J. A. (2004). Reflecting on the development of interpretative phenomenological analysis and its contribution to qualitative research in psychology. Qualitative Research in Psychology, 1, 39-54.

Smith, J. A. (2007). Hermeneutics, human sciences and health: Linking theory and practice. International Journal of Qualitative Studies on Health and Well-Being, 2, 3-11.

Smith, J. A., Flowers, P., \& Larkin, M. (2009). Interpretative phenomenological analysis: Theory, method, and research. Los Angeles: SAGE.

Smith, J. A., Jarman, M., \& Osborn, M. (1999). Doing interpretative phenomenological analysis. In M. Murray \& K. Chamberlain (Eds.), Qualitative Health Psychology: Theories and methods (pp. 218241). Sage.

Smith, J. A., \& Osborn, M. (2008). Interpretative phenomenological analysis. In J. A Smith (Ed.), Qualitative psychology: A practical guide to methods (2nd ed.). London: Sage.

Soka Gakkai. (2021). Daily practice. https://www.sokaglobal.org/practicing-buddhism/daily-practice.html

Soka Gakkai International (SGI)-UK. (2016). Philosophy. http://www.sgi-uk.org/Buddhism

Stein, M. (2017). Where East meets West: In the house of individuation. The Journal of Analytical Psychology, 62(1), 67-87.

Van Gordon, W., Shonin, E., \& Griffiths, M. D. (2015). Towards a second generation of mindfulness-based interventions. Australian \& New Zealand Journal of Psychiatry, 49(7), 591-592.

Van Gordon, W., Shonin, E. \& Griffiths, M.D. Mindfulness (2016). Meditation awareness training for individuals with fibromyalgia syndrome: An interpretative phenomenological analysis of participants' experiences. Mindfulness, 7(2), 409-419. https://doiorg.ezproxy.derby.ac.uk/10.1007/s12671-015-0458-8

Vos, T., Barber, R. M., Bell, B., Bertozzi-Villa, A., Biryukov, S., Bolliger, I., ... \& Brugha, T. S. (2015). Global, regional, and national incidence, prevalence, and years lived with disability for 301 acute and chronic diseases and injuries in 188 countries, 1990-2013: a systematic analysis for the Global Burden of Disease Study 2013. The Lancet, 386(9995), 743-800.

Wallace, B. A. (2003). Introduction: Buddhism and science-Breaking down the barriers. In B. A. Wallace (Ed.), Buddhism and science: Breaking new ground. New York: Columbia University Press.

Wallace, B. A., \& Shapiro, S. L. (2006). Mental balance and well-being: Building bridges between Buddhism and Western psychology. American Psychologist, 61(7), 690.

Watts, A. (1996). The religion of no-religion. Tuttle Publishing.

Weaver, A. J., Vane, A., \& Flannelly, K. J. (2008). A review of research on Buddhism and health: 19802003. Journal of Health Care Chaplaincy, 14(2), 118-132.

Williams, M. J., McManus, F., Muse, K., \& Williams, J. G. (2011). Mindfulness-based cognitive therapy for severe health anxiety (hypochondriasis): An interpretative phenomenological analysis of patients' experiences. British Journal of Clinical Psychology, 50(4), 379-397. https://doi.org/10.1111/j.2044-8260. 2010.02000.x

Wiseman, J., \& Brasher, K. (2008). Community wellbeing in an unwell world: Trends, challenges, and possibilities. Journal of Public Health Policy, 29(3), 353-366.

Wuthnow, R., \& Cadge, W. (2004). Buddhists and Buddhism in the United States: The scope of influence. Journal for the Scientific Study of Religion, 43(3), 363-380.

Yardley, L. (2000). Dilemmas in qualitative health research. Psychology \& Health, 15, 215-228.

Zoysa, N., Ruths, F. A., Walsh, J., \& Hutton, J. (2014). Mindfulness based cognitive therapy for mental health professionals: A long-term qualitative follow-up study. Mindfulness, 5(1), 10-17.

Publisher's Note Springer Nature remains neutral with regard to jurisdictional claims in published maps and institutional affiliations. 